\title{
Should Tuberculosis Prophylaxis Be Given for the Chronically Dialyzed Patients?
}

\author{
Kuddusi Cengiz \\ Department of Nephrology, Ondokuz Mayıs University School of Medicine, Samsun, Turkey
}

Until the middle of this century, tuberculosis was, in Dickens' words, 'a disease which medicine never cured, wealth warded off, or poverty could boast exemption from - which sometimes moves in giant strides, and sometimes at a tardy sluggish pace, but, slow or quick, is ever sure and certain' [1]. Mycobacterium tuberculosis is an extremely successful pathogen that continues to thrive in developing countries and is re-emerging in the industrialized world. Globally, it remains a more frequent cause of death than any other infectious agent [2]. Approximately a third of the world's population is infected with M. tuberculosis, and the World Health Organization estimated that in 1996 there were 8 million new cases of tuberculosis and 3 million deaths from the disease [2]. The sinister synergy between this disease of antiquity and the newer pathogen human immunodeficiency virus is responsible for the death of about a third of all patients with AIDS in Africa [3].

Yet progression to disease and death is far from an inevitable consequence of exposure. There is dramatic variability in the rates of infection among persons exposed to different sources of infection, and of those infected, approximately $90 \%$ never become ill. The inability to predict whose patients are most likely to transmit infection and who among those infected will have the disease and infect others remains a major barrier to optimal public health and patient care.
Host resistance to $M$. tuberculosis is mediated by cellular immunity as this is impaired in patients with chronic renal failure [4], the incidence of tuberculosis in dialyzed patients should be high. Cellular and humoral immune responses are suppressed in uremic subjects [5]. The increase in sister chromatid exchange (SCE), chromosal aberrations, tumor markers and the impaired cell function have been reported [6-8]. Uremia thus induces a remarkable suppression of the immune status. In addition, patients receiving hemodialysis spend prolonged periods of time together in health-care facilities, thereby increasing the potential for tuberculosis transmission if a patient has active disease. For these reasons, routine tuberculosis screening of hemodialysis patients has been recommended [9]. Although the Mantoux tuberculin skin test remains the most useful screening tool, cutaneous anergy decreases the accuracy of the test.

End-stage renal failure patients on chronic dialysis are prone to tuberculous infection due to a defect in cellular immunity. The incidence is reported to be 10-16 times higher than that in the general population [10-14]. One in every 3 people in the world is infected with $M$. tuberculosis, and observed rates of new tuberculosis infection are on the increase, especially in the third world [15-18]. In the 'rich' countries, latent tuberculosis can be reactivated in a number of 'high-risk' patient populations such as AIDS, silicosis, immunosuppression, malnutrition and end-stage renal failure [15-17]. Worldwide tuberculosis

\footnotetext{
Prof. Kuddusi Cengiz, MD

Department of Nephrology

Ondokuz Mayıs University School of Medicine

TR-55139 Samsun (Turkey)
}

Xx+41613061234 E-Mail karger@karger.ch www. karger.com 
infection in dialysis patients ranges from 5 to $25 \%$ [18]. Over $40 \%$ of dialyzed patients with tuberculosis have extrapulmonary manifestations of the disease, and this makes the disease difficult to diagnose, causing delay in commencing curative therapy [18]. For these reasons, tuberculosis prophylaxis in chronically dialyzed patients is worthy of consideration, especially as isoniazid (INH) prophylaxis effectively reduces reactivation of latent tuberculosis for prolonged periods of time [19]. Unfortunately, only one study has addressed this issue in dialyzed patients [20]. In that study, conducted in southern India, 184 hemodialysis patients entered a double-blind, randomized trial of INH prophylaxis. A trend towards protection from tuberculosis was demonstrated [19]. Therefore, a number of questions still need to be answered. What drug should be given for prophylaxis? What are the possible benefits and complications of such therapy? And finally, which dialysis patients should receive tuberculosis prophylaxis?

\section{What Drug Should Be Given for Prophylaxis?}

The drug of choice is INH. It has excellent oral absorption. It is bactericidal and can be given once every 2-3 days. There is no need for dose reduction in patients with impaired renal function and it is very cheap [21]. The effectiveness of INH in preventing tuberculosis is unquestionable. At least $50-60 \%$ of treated patients will enjoy long-term protection from tuberculosis after a 6-month period of therapy, and in some conditions protection rises to $90 \%[22,23]$. Salpeter et al. [24] also argue that INH prophylaxis, for all low-risk tuberculin skin test reactors older than 35 years of age, will prevent thousands of tuberculosis-related deaths. INH prophylaxis is successful, if the drug is taken under supervision, on a two or three times weekly basis $(15 \mathrm{mg} / \mathrm{kg} /$ dose $)$, a perfect solution for hemodialysis patients [16].

Hepatotoxicity remains the major problem associated with INH administration, especially in the elderly, the malnourished and in the alcoholic $[16,25]$. It generally occurs within the first 4-8 weeks of therapy, but in $20 \%$ of patients minor and asymptomatic elevation of hepatic enzymes occur, which is transient and does not necessitate cessation of INH treatment [16]. When transaminase levels increase to 2-3 times above normal, then INH must be stopped. But what of fetal INH-induced hepatitis? In 1996, after monthly liver function monitoring had become the accepted norm, Millard et al. [26] showed that, irrespective of age, the rate of fatal hepatitis is 1-2/
100,000 treated patients. Also, McGlynn et al. [27] failed to show a greater degree of INH hepatotoxicity in hepatitis B carriers. This observation may be relevant for dialysis patients who are infected with the hepatitis B virus.

Nervous system side effects have been documented in dialysis patients treated with INH [28]. INH inhibits phosphorylation of pyridoxine, and this leads to a reduced production of pyridoxal-5-phosphate, a co-enzyme essential in neurotransmission. In dialysis patients, serum pyridoxine levels are normal, but pyridoxine metabolism is not, and the addition of INH therapy makes these patients vulnerable to neurological toxicity. Fortunately, this problem is completely and easily avoidable by concurrent administration of INH and vitamin $\mathrm{B}_{6}(100 \mathrm{mg} /$ day) [28].

For persons possibly infected with tuberculous resistant to INH, various alternative therapies have been used [16]. Monotherapy with rifampin is effective, and if maintained for 6 months has a low incidence of side effects [29]. Another drug protocol currently under investigation is combined rifampin and pyrazinamide, with a duration of therapy lasting only 2 months [25].

\section{Which Dialysis Patients Should Receive Tuberculosis Prophylaxis?}

According to our current knowledge, any patients with a positive Mantoux skin test (5 U purified protein derivative of tuberculin - a sterile-killed concentrate obtained from human tubercle bacilli), should be considered to be infected with $M$. tuberculosis, even if they have previously received $\mathrm{BCG}$ vaccine $[22,30]$. An indurated area of at least $10 \mathrm{~mm}, 48-72 \mathrm{~h}$ after intradermal injection, is positive in non-AIDS-infected, dialyzed patients; while in persons with $\mathrm{x}$-ray findings consistent with healed tuberculosis or who have been in close contact with patients known to be infected with pulmonary tuberculosis, then an indurated area of $5 \mathrm{~mm}$ is regarded as positive [22]. If chronically dialyzed patients are regarded at 'high risk' for reactivation of latent tuberculosis, then one may be tempted to treat all dialysis patients with a positive tuberculin skin test. At the very least, any dialyzed patient with a positive tuberculin skin test and who lives or has migrated from an endemic area, has had close contact with any patient with active pulmonary tuberculosis, is a recent tuberculin test converter or has a x-ray suggestive of old tuberculosis, should receive prophylaxis. Woeltje et al. [17] advised regular tuberculin skin testing and encouraged INH prophylaxis in hemodialyzed patients. 
Uremia impairs cell-mediated immunity and is known to cause anergy. When a high index of suspicion for tuberculosis exists, but the skin test is negative, then it should be repeated with $250 \mathrm{U}$ dose. If this high-dose skin test is negative, then skin tests with other antigens should be performed. A negative reaction to these tests indicate anergic state [22]. Furthermore, false negative results on tuberculin skin testing can be caused by faulty test administration or interpretation, corticosteroid therapy, malnutrition, acute viral disease, candida infection or overwhelming tuberculosis. But recent studies have demonstrated that properly performed, multiple skin tests will be positive in over $60 \%$ of dialyzed patients [17]. If dialysis patients have a 'true negative' tuberculin skin test and no other risk factors associated with reactivation of tuberculosis, than they, most probably, should not be treated.
In conclusion, particularly in the developing countries tuberculosis incidence and mortality are higher than expected and found in the patients undergoing hemodialysis. Diagnosis of tuberculosis is obscured because the symptoms are nonspecific and attributable to uremia. INH prophylaxis is cost-effective in 'high-risk' populations for tuberculosis. INH prevents hospitalizations, eliminates a possible need for multidrug therapy for active tuberculosis at a later date, and reduces mortality [16]. Therefore, there are good reasons for tuberculosis prophylaxis to be given to chronically dialyzed patients. This policy was recommended by the Advisory Council for the elimination of tuberculosis [31]. Prospective, double-blind, randomized studies will clarify the need of tuberculosis prophylaxis for dialyzed patients, particularly in areas highly endemic for tuberculosis.

\section{References}

1 Dickens C: Nicholas Nickleby. New York, Dodd Mead, 1949, 545.

2 Murray CJL, Lopez AD (eds): The global burden of disease. Global Burden of Disease and Injury Series, vol 1. Cambridge, Harvard University Press, 1996, pp 345-350.

3 Lucas SB, Hounnou A, Peacock C, Beaumel A, Djomand G, Yeboue K, Honde M, Diamande M, Giordano C: The mortality and pathology of HIV infection in a west African city. AIDS 1993;7:1569-1579.

4 Newberry WM, Sanford JP: Defective cellular immunity in renal failure: Depression of reactivity of lymphocytes to phytohemagglutinin by renal failure serum. J Clin Invest 1971;50: 1262-1271.

5 Wilson WEC, Kirpatrick CH, Talmage DW: Suppression of immunologic responsiveness in uremia. Ann Intern Med 1965;62:1.

6 Cengiz K, Block AW, Hossfeld DK, Anthone $\mathrm{R}$, Anthone S, Sandberg AA: Sister chromatid exchange and chromosome abnormalities in uremic patients. Cancer Genet Cytogenet 1988;36:55-67.

7 Eskiocak S, Dörtok H, Alvur M, Cengiz K: Tumor markers in chronic renal failure and hemodialysis. Nephrol Dial Transplant 1995; 10:1256.

8 Dobbelstein $\mathrm{H}$ : Immune system in uremia. Nephron 1976;17:409-414.

9 Centers for Disease Control: Screening for tuberculosis and tuberculosis infection in highrisk populations. MMWR 1995;44:19-34.

10 Garcia-Leoni ME, Martin-Scapa C, Rodena P, Morena S, Bouza E: High incidence of tuberculosis in renal patients. Eur $\mathbf{J}$ Clin Microbial Infect Dis 1990;9:283-285.

11 Papadimitriou M, Memmos D, Metaxas P: Tuberculosis in patients on regular hemodialysis. Nephron 1979;24:53-57.
12 Lundin AP, Adler AJ, Berlyne GM, Friedman EA: Tuberculosis in patients undergoing maintenance hemodialysis. Am J Med 1979;67: 597-602.

13 Sasaki S, Akiba T, Suenaga M, Suenaga M, Tomura S, Yashiyama N, Naka ST, Sasaoka T, Takeuchı J: Ten-year survey of dialysis-associated tuberculosis. Nephron 1979;24:141-145.

14 Mitwalli A: Tuberculosis in patients on maintenance dialysis. Am J Kidney Dis 1991;18:579_ 582.

15 Vas SI: Renaissance of tuberculosis in the 1990s: Lessons for the nephrologist. Perit Dial Int 1994;14:209-214.

16 Krance MB, Fisher MA: Prophylaxis of mycobacterial infections in immunocompromised patients. Am Fam Physician 1996;54:19811987.

17 Woeltje KF, Mathew A, Rothstein M, Seiler S, Fraser VJ: Tuberculosis infection and anergy in hemodialysis patients. Am J Kidney Dis 1998; 31:848-852.

18 Cengiz K: Increased incidence of tuberculosis in patients undergoing hemodialysis. Nephron 1996;73:421-424.

19 Korzets K, Gafter U: Tuberculosis prophylaxis for the chronically dialysed patient - Yes or no? Nephrol Dial Transplant 1999;14:2857-2859.

20 John GT, Thomas PP, Thomas M, Jeyaseelan L, Jacob CK, Shastry JCM: A double-blind randomised controlled trial of primary isoniazid prophylaxis in dialysis and transplant patients. Transplantation 1994;57:1683-1684.

21 Ellard GA: Chemotherapy of tuberculosis for patients with renal impairment. Nephron 1993;64:169-181.

22 Amin NM: Tuberculin skin testing. Can it contain the impending tuberculosis epidemic? Postgrad Med 1994;95:46-53.
23 Dolan JG, Bordley DR: Isoniazid prophylaxis: The importance of individual values. Med Decis Making 1994;14:1-8.

24 Salpeter SR, Sanders GD, Salpeter EE, Owens DC: Monitored isoniazid prophylaxis for all low-risk tuberculin reactors older than 35 years of age - A risk-benefit and cost-effectiveness analysis. Ann Intern Med 1997;127:10511061.

25 Bishai WR, Chaisson RE: Short-course chemoprophylaxis for tuberculosis. Clin Chest Med 1997; 18:115-122.

26 Millard PS, Wilcosky TC, Reade-Christopher SJ, Weber DJ: Isoniazid-related fatal hepatitis. West J Med 1996;164:486-491.

27 McGlynn KA, Lustbader ED, Sharrar RG, Murphy EC, London WT: Isoniazid prophylaxis in hepatitis B carriers. Am Respir Dis 1986; 134:666-668.

28 Siskind MS, Thuenemann D, Kirlin L: Isoniazid-induced neurotoxicity in chronic dialysis patients: Report of 3 cases and a review of the literature. Nephron 1993;64:303-306.

29 Villarino ME, Ridzon R, Weismuller P, Elcock M, Maxwell RM, Meador J, Smith PJ, Carson ML, Geiter LJ: Rifampin-preventive therapy for tuberculosis infection. Experience with 157 adolescents. Am J Respir Crit Care Med 1997; 155:1735-1738.

30 Carosi G, Matteelli A: Prophylaxis for tuberculosis in Europe - Ongoing research. Clin Infect Dis 1996;22(suppl 1):55-60.

31 Centers for Disease Control: Screening for tuberculosis in high-risk population and the use of preventative therapy for tuberculosis infection in the United States. Recommendations of the Advisory Council for the elimination of tuberculosis. MMWR 1990;39:1-12. 